\title{
Urinary Tract Infection in Postmenopausal Women
}

\author{
Raul Raz \\ Infectious Diseases Unit, Ha'Emek Medical Center, Afula, Rappaport Faculty of Medicine, Technion, Haifa, Israel
}

Urinary tract infection (UTI) is the most common bacterial infection in women in general and in postmenopausal women in particular. Two groups of elderly women with recurrent UTI should be differentiated regarding age and general status: healthy, young postmenopausal women aged 50 to 70 years who are neither institutionalized or catheterized and elderly institutionalized women with or without a catheter. Bacteriuria occurs more often in elderly functionally impaired women, but in general it is asymptomatic. However, the risk factors associated with recurrent UTI in elderly women are not widely described. In a multivariate analysis it was found that urinary incontinence, a history of UTI before menopause, and nonsecretor status were strongly associated with recurrent UTI in young postmenopausal women. Another study described the incidence and risk factors of acute cystitis among nondiabetic and diabetic postmenopausal women. Independent predictors of infection included insulin-treated patients and a lifetime history of urinary infection. Borderline associations included a history of vaginal estrogen cream use in the past month, kidney stones, and asymptomatic bacteriuria at baseline. Another important factor in postmenopausal women is the potential role that estrogen deficiency plays in the development of bacteriuria. There are at least two studies showing a beneficial effect of estrogen in the management of recurrent bacteriuria in elderly women. One of these studies showed that vaginal estrogen cream reduced vaginal $\mathrm{pH}$ from $5.5 \pm 0.7$ to $3.6 \pm 1.0$, restored lactobacillus, and decreased new episodes of UTI. Another study reported similar results using an estriol vaginal ring. However, contradictory results are found in the literature. For example, additional studies found that the use of estriol-containing vaginal pessaries was less effective than oral nitrofurantoin macrocrystals in preventing UTI in postmenopausal women. Two other studies also did not find any benefit in the reduction of UTI by oral estrogen therapy. Unfortunately, the use of estrogen in preventing UTI in postmenopausal women remains questionable. New strategies have been researched for reducing the use of antibiotics in the prevention and treatment of UTI. Two of them are probiotics and cranberry juice or capsules. Although several studies regarding probiotics and cranberry juice or capsules have reported a reduction of episodes of UTI, there is no conclusive evidence that they are useful in the prevention of UTI in postmenopausal women. As for the optimal drug, dosage, and length of treatment for UTI in the elderly, there are no studies comparing these data with the treatment for young women.

Key Words: Bacteriuria elderly women; Postmenopausal women; Urinary tract
infections

This is an Open Access article distributed under the terms of the Creative Commons Attribution Non-Commercial License (http://creativecommons.org/licenses/by-nc/3.0) which permits unrestricted non-commercial use, distribution, and reproduction in any medium, provided the original work is properly cited.

\author{
Article History: \\ received 19 August, 2011 \\ accepted 30 September, 2011
}

Corresponding Author:

Raul Raz

Infectious Diseases Unit, Ha'Emek Medical Center, Afula, Rappaport Faculty of Medicine, Technion, Haifa, Israel

TEL: +00972-6-652-4259

FAX: +00972-6-659-5689

E-mail: raz_r@clalit.org.il

This manuscript was published originally in: Naber KG, Schaeffer AJ, Heyns CF, Matsumoto T, Shoskes DA, Bjerklund Johansen TE (eds): Urogenital Infections. European Association of Urology - International Consultation on Urological Diseases, 1st edition 2010, Arnhem, The Netherlands, ISBN:978-90-7975441-0. 


\section{INTRODUCTION}

Urinary tract infection (UTI) is the most common bacterial infection in young and elderly women. Despite the higher incidence of bacteriuria in elderly women, most UTI research has been conducted in young women. This chapter will discuss epidemiological studies regarding risk factors associated with bacteriuria in elderly women. Bacteriuria in the elderly is associated with high mortality rates; however, in most cases, bacteriuria is asymptomatic and not a causal factor of death.

Estrogen deficiency plays an important role in the development of bacteriuria. Several studies have been conducted showing the efficacy of estrogen (orally and vaginally) in the prevention of UTI. Yet, the literature is divided on this subject, and other studies have not shown any advantage in using estrogen.

This chapter will focus on the updated known data regarding the use of estrogen in the prevention of bacteriuria in elderly women. The alarming increase in multidrug-resistant uropathogens makes it imperative that alternative strategies are found. One strategy is the restoration of flora with lactobacilli using probiotics and another is the use of cranberry, a competitive compound that inhibits the attachment of bacteria to the uroepithelial mucosa and thereby reduces the frequency of UTI.

\section{METHODOLOGY}

A systematic literature search was performed of studies conducted over the past 15 years. A few recent studies have investigated the management of UTI in postmenopausal women. The data were collected from the most up-to-date published studies and guidelines, which were found by searching Medline, PubMed, and the Cochrane database with the following key words: 'bacteriuria in elderly women' and 'postmenopausal women and UTI'. A total of 190 papers were screened by title and abstract: 111 for the first keyword and 79 for the second. Only English publications addressing the keywords were screened.

The 25 references used in the text were assessed according to the level of scientific evidence involved. The studies were rated according to the level of evidence $(\mathrm{LoE})$ and the grade of recommendations (GoR) by using ICUD standards $[1,2]$.

\section{DEMOGRAPHY}

UTI is the most common bacterial infection in women. Three groups of women with recurrent UTI should be distinguished on the basis of age: premenopausal women, healthy postmenopausal women between the ages of 50 to 70 years who are neither institutionalized nor catheterized, and elderly institutionalized women, who are in many cases catheterized.

Bacteriuria occurs more often in functionally impaired women than in those who are not impaired; persistent bac- teriuria is seen more often in nursing home residents, and transient bacteriuria is seen more often in young, healthy postmenopausal women. The majority of elderly women with bacteriuria are asymptomatic and should not be treated with antibiotics ( $\operatorname{LoE} 1 \mathrm{~b}$ ) [3,4]. In young to middle-aged women, the prevalence of UTI is $<5 \%$, rising considerably with advancing age. Epidemiologic studies have shown that $15 \%$ to $20 \%$ of $65-70$ year-old women have bacteriuria, compared with $20 \%$ to $50 \%$ of women $>80$ years old.

Despite the high incidence of bacteriuria in postmenopausal women (young and institutionalized), most UTI research has been conducted in younger women. Hence, the most common UTI risk factors among healthy younger women, such as frequent vaginal intercourse, spermicide use, diaphragm use, condom use, a previous UTI history, recent antibiotic use, and nonsecretor status, were not widely investigated in middle-aged and elderly women (LoE 2a) [5].

\section{BACTERIURIA IN YOUNG VS. ELDERLY WOMEN}

Foxman et al conducted a case-control study investigating the role of health behavior and sexual and medical history in UTI risk among otherwise healthy women aged 40 to 65 years [4]. They showed that sexual activity was not associated with acquiring UTI in this age group, whereas a history of UTI during the past year, urine loss, antibiotic use during the previous 2 weeks, and exposure to cold during the previous 2 weeks were positively associated with UTI. In addition, drinking cranberry juice and taking vitamin $\mathrm{C}$ were moderately protective ( $\mathrm{LoE} 2 \mathrm{~b}$ ) [4].

\section{RISK FACTORS}

A case-control study compared 149 postmenopausal women with a history of recurrent UTI with 53 age-matched women with no history of UTI. They looked for risk factors in healthy noninstitutionalized and noncatheterized women. Three urological factors, namely, incontinence ( $41 \%$ of case patients vs. $9 \%$ control patients; $p<0.001$ ), presence of a cystocele ( $19 \%$ vs. $0 \% ; p<0.001)$, and postvoiding residual volume ( $28 \%$ vs. $2 \% ; p<0.000008)$ were strongly associated with recurrent UTI. Multivariate analysis showed that urinary incontinence (odds ratio [OR], $5.79 ; 95 \%$ confidence interval [CI], 2.05-16.42; $\mathrm{p}=0.0009$ ), a history of UTI before menopause (OR, $4.85 ; 95 \%$ CI, 1.7-13.84; $\mathrm{p}<0.003$ ), and nonsecretor status (OR, 2.9; 95\% CI, 1.28-6.25; $\mathrm{p}=0.005$ ) were most strongly associated with recurrent UTI in postmenopausal women (LoE 2a) [5].

Jackson et al described the incidence and risk factors for acute cystitis among nondiabetic and diabetic postmenopausal women and the possible effect of estrogens on those women ( $\operatorname{LoE} 2 \mathrm{a}$ ) [6]. During 1,773 person-years of follow-up, 138 symptomatic UTIs occurred (incidence, 0.07 person-year). Independent prediction of infection included insulin-dependent diabetes mellitus (hazard ratio 95\% CI, 1.7-7.0) and a lifetime history of UTI (hazard ratio for six 
or more infections, $6.9 ; 95 \%$ CI, 3.5-13.6). However, a borderline association included a history of vaginal estrogen cream use in recent months (hazard ratio, 1.8; 95\% CI, 1.0-3.4), and a history of kidney stones (hazard ratio, 1.95; 95\% CI, 0.9-3.5). However, sexual activity, urinary incontinence, parity, postcoital urination, vaginal dryness, use of cranberry juice, vaginal bacterial flora, and postvoid residual bladder volume were not associated with the incidence of acute cystitis after multivariable adjustment.

A study by Moore et al found that recent sexual intercourse, as described for younger women, was also strongly associated with incident UTI in other healthy postmenopausal women (LoE 2b) [7]. In the older, institutionalized women, urine catheterization and functional status deterioration appeared to be the most important risk factors associated with UTI (LoE 2a) [8]. The risk of UTI increases dramatically with catheterization. Table 1 describes the major factors predisposing adult women to UTI as related to age [9].

\section{BACTERIURIA AND MORTALITY}

Bacteriuria has been discovered as a cause of increased mortality in elderly individuals. Studies of Greek, Finnish, and American patients showed decreased longevity associated with UTI (LoE 1b) [10-12]. The elderly patients with UTI were suffering from a variety of diseases other than UTI that might have increased their susceptibility to infections as well as their mortality.

Nordestam et al studied a population of elderly patients and compared their longevity in relation to bacteriuria (LoE 1b) [13]. There was no increase in mortality related to bacteriuria for otherwise healthy individuals. Bacteriuria per se did not appear to be a risk factor for mortality. In patients with concomitant disease, bacteriuria was associated with increased mortality, but it is not the cause.

\section{THE ROLE OF ESTROGEN}

Another important factor in postmenopausal women is the potential role that estrogen deficiency plays in the develop-

TABLE 1. Major factors predisposing adult women to UTI as related to age [9]

\begin{tabular}{|c|c|}
\hline Age group (yr) & Predisposing factor \\
\hline $15-50$ & $\begin{array}{l}\text { Sexual intercourse, Diaphragm/spermicide, } \\
\text { Spermicide, Antimicrobials, Prior UTI, } \\
\text { Maternal history of UTI, Childhood history } \\
\text { of UTI, Nonsecretor status }\end{array}$ \\
\hline $50-70$ & $\begin{array}{l}\text { Lack of estrogen, Urogenital surgery, } \\
\text { Incontinence, Cystocele, Postvoid residual } \\
\text { urine, Nonsecretor status, Prior UTI }\end{array}$ \\
\hline$>70$ & $\begin{array}{l}\text { Catheterization, Incontinence, Urogenital } \\
\text { surgery }\end{array}$ \\
\hline
\end{tabular}

UTI: urinary tract infection ment of bacteriuria. Postmenopausal women frequently present with genitourinary symptoms; half have genitourinary disorders, and $29 \%$ have urinary incontinence ( $\operatorname{LoE} 1 b$ ) [14]. Postmenopause is characterized by a significant reduction in ovary estrogen secretion, which is often associated with vaginal atrophy. Clinically, it manifests as a syndrome characterized by vaginal dryness, itching, dyspareunia, and urinary incontinence. This may sometimes imitate a UTI (LoE 2a) $[15,16]$.

Estrogen stimulates the proliferation of lactobacillus in the vaginal epithelium, reduces $\mathrm{pH}$, and avoids vaginal colonization of Enterobacteriaceae, which are the main pathogens of the urinary tract. Fig. 1 describes the relationship between estrogen and the vaginal flora and the pathophysiology of urinary tract infections in elderly women ( $\mathrm{LoE} 1 \mathrm{a})$ [17]. In addition, the absence of estrogen decreases the volume of the vaginal muscles, resulting in slackness of the ligaments holding the uteric pelvic floor and the bladder, resulting in the development of prolapse of the internal genitalia. Kicovic et al showed that vaginal cream decreased urogenital complaints associated with atrophic vaginitis $(\operatorname{LoE} 1 b)$ [18].

A previous randomized, double-blind, placebo-controlled study demonstrated that vaginal estriol treatment had a dramatic effect on recurrent UTIs in postmenopausal women. The results showed that the incidence of UTI in women who received vaginal estriol was reduced to $0.5 \mathrm{epi}$ sodes per year compared with 5.9 episodes per year in women who received placebo. In addition, after 1 month of treatment, lactobacillus appeared in $60 \%$ of the estrogen-treated group but in none of the placebo group, and the vaginal $\mathrm{pH}$ decreased from $5.5 \pm 0.7$ before treatment to $3.6 \pm 1.0$ after treatment ( $\operatorname{LoE} 1 \mathrm{a})$ [19].

Several years later, similar results were obtained by Eriksen, using an estradiol-vaginal ring ( $\operatorname{LoE} 1 b)$ [20]. In that study, the women in the estradiol group had a significant reduction in the frequency of urogenital symptoms, such as vaginal dryness, dyspareunia, and urge and stress incontinence after 36 weeks of study. In addition, $45 \%$ of the women receiving estradiol were still free of UTI, in contrast with only $20 \%$ of the women treated with placebo.

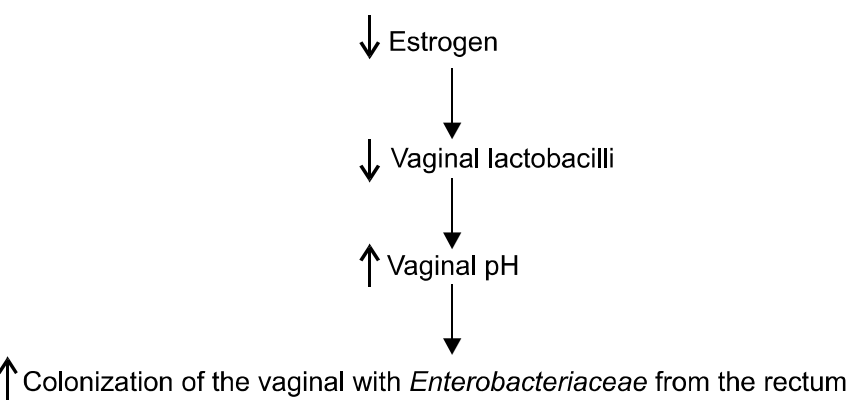

Fig. 1. Relationship between estrogen and the vaginal flora and pathophysiology of urinary tract infections in elderly women [17]. 
However, contradicting results are found in the literature. For example, another study showed that the use of estriol-containing vaginal pessaries was less effective than the use of oral nitrofurantoin macrocrystals in the prevention of bacteriuria in postmenopausal women. This study also showed the failure of the estriol-containing vaginal pessaries to restore vaginal lactobacilli and to reduce vaginal $\mathrm{pH}$ in those women ( $\operatorname{LoE} 1 \mathrm{a})$ [21].

Brown et al assessed the effects of hormonal therapy on UTI frequency and examined potential risk factors ( $\mathrm{LoE} 3)$ [22]. They used data from the Health and Estrogen/Progesterone Replacement Study, a randomized, blinded trial of the effect of hormone therapy on coronary heart disease events among 2,763 postmenopausal women aged 44 to 79 years with coronary diseases. UTI frequency was higher in the group receiving hormone treatment $(0.625 \mathrm{mg}$ conjugated estrogen plus $2.5 \mathrm{mg}$ medroxyprogesterone acetate or placebo followed for a mean of 4.1 years), although the difference was not statistically significant. Statistically significant risk factors for UTI in the multivariate analysis included the following: women with diabetes mellitus in treatment (insulin OR, 1.81; 95\% CI, 1.4-2.34), oral medication (OR, 1.44; 95\% CI, 1.09-1.9), poor health (OR, 1.34; 95\% CI, 1.14-1.57), vaginal itching (OR, 1.63; 95\% CI, 1.07-2.5), and urge incontinence (OR, 1.51;95\% CI, $1.30-1.75)$. UTIs in the previous years were strongly associated with a simple UTI (OR, 7.00; 95\% CI, 5.91-8.92) as well as with multiple UTIs (OR, 18.51; 95\% CI, 14.27-24.02).

Jackson et al did not see that the use of oral or vaginal estrogen was a protective factor in order to avoid recurrent UTI (LoE 2a) [6].

In conclusion, the efficacy of estrogen in the prevention of UTI in postmenopausal women with recurrent infections remains questionable. From a clinical perspective, the main currently recommended use of estrogen (probably vaginal and not oral) is in postmenopausal women, especially those infected with multidrug-resistant uropathogens, which limits the options and effectiveness of antimicrobial prophylaxis, and in women in whom the symptoms are related to atrophic vaginitis (5). Table 2 summarizes the indications and contraindications for estrogen therapy in UTI [3].

\section{TREATMENT}

Treatment of acute cystitis and pyelonephritis in otherwise healthy postmenopausal women is similar to that in premenopausal women; however, short- term therapy in postmenopausal women is not as well documented by controlled studies as in younger women. Raz and Rozenfeld published a study in postmenopausal women (mean age 65 years) with uncomplicated UTI in which ofloxacin, $200 \mathrm{mg}$ once daily for 3 days ( $\operatorname{LoE} 1 \mathrm{~b}$ ) [23], was significantly more effective in both short- and long-term follow-up than a 7 day course of cephalexin, $500 \mathrm{mg}$ four times daily, even though all the uropathogens were susceptible to the two agents. In another double-blind study ( $\operatorname{LoE} 1 \mathrm{~b}$ ), including a total of 183 postmenopausal women of at least 65 years of age with acute uncomplicated UTI, similar results were obtained with either a 3-day or a 7-day oral course of ciprofloxacin $250 \mathrm{mg}$ two times daily (bacterial eradication 2 days after treatment $98 \%$ vs $93 \%, \mathrm{p}=0.16$ ), but the shorter course was better tolerated. The rate of bacterial eradication in this study was generally high, and the rate of bacterial resistance to ciprofloxacin low (GoR A) [24].

Asymptomatic bacteriuria in elderly women should not be treated with antibiotics (GoR A).

The optimal antimicrobials, dosages, and duration of treatment in elderly women appeared to be similar to those recommended for young postmenopausal women (GoR C). However, these results should not be extended to the frail elderly geriatric population with significant comorbidities, who frequently present with UTI caused by more resistant Gram-negative organisms and in whom treatment duration should be prolonged as in complicated UTI.

Estrogen (especially vaginal) could be administered for prevention of UTI; yet, the results are conflicting (GoR C). There are at least two clinical studies showing that vaginal estriol and estradiol-releasing vaginal rings restore vaginal flora, reduce $\mathrm{pH}$, and reduce the number of symptomatic bacteriuria $[19,20]$. However, it appears that oral estrogen does not reduce the incidence of UTI in postmenopausal women (Hooton et al).

Alternative methods, like cranberry and probiotic lacto-

TABLE 2. Indications and contraindications for estrogen therapy in UTI [3]

\begin{tabular}{lc}
\hline \multicolumn{2}{c}{ Indications } \\
\hline $\begin{array}{l}\text { Oral therapy } \\
\text { - Young postmenopausal } \\
\text { women }\end{array}$ & Advantages \\
& - Avoid menopausal \\
& symptoms \\
& - Prevent osteoporosis \\
& - Prevent ischemic heart \\
& disease \\
& - Prevent UTI \\
Vaginal therapy & Advantages \\
- Women $>60$ years old & - Improve symptoms related \\
& to atrophic vaginitis \\
& - Improve urge incontinence \\
& - Prevent UTI \\
\hline \multicolumn{2}{c}{ Contraindications } \\
\hline Absolute & Relative \\
- Endometrial carcinoma & - High blood pressure? \\
- Breast carcinoma & - Diabetes mellitus? \\
- Thromboembolic disorders & - Gallstones? \\
- Liver disease & \\
\hline \multicolumn{2}{c}{ Difficulties in vaginal therapy } \\
\hline
\end{tabular}

Physical limitations

Tremor, obesity, status after cerebrovascular accident, dementia, psychological problems, education/cultural behavior 
bacilli, can contribute to preventing recurrent UTI in postmenopausal women, but more well-conducted studies are required to define their exact role and efficiency (GoR C). Once complicating factors, such as urinary obstruction, neurogenic bladder disturbances, etc, can be ruled out, an antimicrobial prophylaxis should be carried out as recommended for premenopausal women (GoR C).

\section{NEW STRATEGIES}

The alarming increase in multidrug-resistant uropathogens makes it imperative that alternative strategies are found. One strategy is the restoration of the normal flora with lactobacilli using probiotics. Another option is the use of a competitive compound that inhibits attachment of bacteria to the uroepithelium. Unfortunately, both methods have been evaluated without conclusive results, although there is some evidence that probiotics and cranberry are useful in preventing UTI.

Reid et al demonstrated the possibility of preventing uropathogen infection by using lactobacillus in vitro [25]. Several clinical studies showed that L. rhamnosus Gr-1 and $L$. fermentum-RC can colonize the vagina, a first step in preventing bacteriuria ( $\mathrm{LoE} 2 \mathrm{a}$ ). However, more studies, especially clinical studies, should be carried out to determine the role of probiotics in the prevention of UTI.

Another possibility is the use of cranberry. Cranberries contain a proanthocyanidin that can prevent the colonization of the E. coli uropathogen in the vaginal mucosa and reduce the frequency of bacteriuria (GoR C) [26]. McMurdo et al carried out a randomized controlled trial in elderly women to compare the efficacy in preventing UTI of cranberry capsules with trimethoprim (GoR C) [27]. The time to first recurrence of UTI was not significantly different between groups. In addition, trimethoprim had a very limited advantage over cranberry in the prevention of recurrent UTI in older women but had more adverse effects and withdrawals.

However, few clinical studies have been conducted, although in small and heterogenic populations, an advantage in the use of cranberry juice or other oral preparations in the prevention of bacteriuria has been shown. In the elderly population, there is only one clinical quasi-randomized study in elderly women with asymptomatic bacteriuria, which showed that bacteriuria and pyuria were significantly reduced in women taking cranberry juice in comparison with women who received placebo (GoR C) [28]. Because asymptomatic bacteriuria in the elderly is not treated, however, the clinical significance of this study remains inconclusive.

\section{FURTHER RESEARCH}

Further wide-scale randomized studies are essential to define and establish the exact role of estrogen therapy, probiotics, lactobacilli, and other possible and available methods to reduce the use of antibiotics.

\section{CONCLUSIONS}

Bacteriuria, particularly asymptomatic bacteriuria, is a very frequent finding in both healthy postmenopausal and institutionalized women. Urological factors, such as urinary incontinence, presence of any grade of cystocele and postvoiding residual volume, together with previous UTI and nonsecretor status, are associated with recurrent UTI in this population. Some studies showed a relationship between bacteriuria with diabetes or sexual intercourse. The role of vaginal or oral estrogen together with the use of probiotics and lactobacilli remains questionable.

\section{Conflicts of Interest}

The authors have nothing to disclose.

\section{REFERENCES}

1. Abrams P, Khoury S, Grant A. Evidence--based medicine overview of the main steps for developing and grading guideline recommendations. Prog Urol 2007;17:681-4.

2. Oxford Centre for Evidence.based medicine. Levels of evidence (March 2009). http://www.cebm.net

3. Raz R. Hormone replacement therapy or prophylaxis in postmenopausal women with recurrent urinary tract infection. $J$ Infect Dis 2001;183(Suppl 1):S74-6.

4. Foxman B, Somsel P, Tallman P, Gillespie B, Raz R, Colodner R, et al. Urinary tract infection among women aged 40-65: behavioral and sexual risk factors. J Clin Epidemiol 2001;54:710-8.

5. Raz R, Gennesin Y, Wasser J, Stoler Z, Rosenfeld S, Rottensterich $\mathrm{E}$, et al. Recurrent urinary tract infections in postmenopausal women. Clin Infect Dis 2000;30:152-6.

6. Jackson SL, Boyko EJ, Scholes D, Abraham L, Gupta K, Fihn SD. Predictors of urinary tract infection after menopause: a prospective study. Am J Med 2004;117:903-11.

7. Moore EE, Hawes SE, Scholes D, Boyko EJ, Hughes JP, Fihn SD. Sexual intercourse and risk of symptomatic urinary tract infection in post-menopausal women. J Gen Intern Med 2008;23: 595-9.

8. Nicolle LE. Asymptomatic bacteriuria in the elderly. Infect Dis Clin North Am 1997;11:647-62.

9. Stamm WE, Raz R. Factors contributing to susceptibility of postmenopausal women to recurrent urinary tract infections. Clin Infect Dis 1999;28:723-5.

10. Dontas A, Kasviki-Charvati PC, Papanayiotou P, Marketos SG. Bacteriuria and survival in old age. N Engl J Med 1981;304: 939-43.

11. Nordenstam G, Brandberg A, Odén AS, Svanborg Edén C, Svanborg A. Bacteriuria and mortality in an elderly population. N Engl J Med 1986;314:1152-6.

12. Platt R, Polk BF, Murdock B, Rosner B. Mortality associated with nosocomial urinary tract infection. N Engl J Med 1982;307: 637-42.

13. Nordenstam G, Sundh V, Lincoln K, Svanborg A, Edén CS. Bacteriuria in representative population samples of persons aged 72-79 years. Am J Epidemiol 1989;130:1176-86.

14. Iosif CS, Bekassy Z. Prevalence of genitor-urinary symptoms in the late menopause. Acta Obstet Gynecol Scand 1984;63:257-60.

15. Haspels AA, Luisi M, Kicovic PM. Endocrinological and clinical investigations in post-menopausal women following admin- 
istration of vaginal cream containing oestriol. Maturitas 1981; 3:321-7.

16. Thomas TM, Plymat KR, Blannin J, Meade TW. Prevalence of urinary incontinence. Br Med J 1980;281:1243-5.

17. Raz R. Role of estriol therapy for women with recurrent urinary tract infections: advantages and disadvantages. Inf Dis in Clinical Practice 1999;8:64-6.

18. Kicovic PM, Cortes-Prieto J, Milojević S, Haspels AA, Aljinovic A. The treatment of postmenopausal vaginal atrophy with ovestin vaginal cream or suppositories: clinical, endocrinological and safety aspects. Maturitas 1980;2:275-82.

19. Raz R, Stamm WE. A controlled trial of intravaginal estriol in postmenopausal women with recurrent urinary tract infections. N Engl J Med 1993;329:753-6.

20. Eriksen B. A randomized, open, parallel-group study on the preventive effect of an estradiol-releasing vaginal ring (Estring) on recurrent urinary tract infections in postmenopausal women. Am J Obstet Gynecol 1999;180:1072-9.

21. Raz R, Colodner R, Rohana Y, Battino S, Rottensterich E, Wasser I, et al. Effectiveness of estriol-containing vaginal pessaries and nitrofurantoin macrocrystal therapy in the prevention of recurrent urinary tract infection in postmenopausal women. Clin Infect Dis 2003;36:1362-8.
22. Brown JS, Vittinghoff E, Kanaya AM, Agarwal SK, Hulley S, Foxman B. Urinary tract infections in postmenopausal women: Effect of hormone therapy and risk factors. Obstes Gynecol 2001;98:1045-52.

23. Raz R, Rozenfeld S. 3-day course of ofloxacin versus cefalexin in the treatment of urinary tract infection in post-menopausal women. Antimicrob Agents Chemother 1996;40:2200-1.

24. Vigel T, Verreault R, Gourdeau M, Morin M, Grenier-Gosselin L, Rochette L. Optimal duration of antibiotic therapy for uncomplicated urinary tract infection in older women: a double-blind randomized controlled trial. CMAJ 2004;170:469-73.

25. Reid G, Burton J. Use of lactobacillus to prevent infection by pathogenic bacteria. Microbes Infect 2002;4:319-24.

26. Raz R. Urinary tract infection in elderly women. Int J Antimicr Agents 1998;10:177-9.

27. McMurdo ME, Argo I, Phillips G, Daly F, Davey P. Cranberry or trimethoprim for the prevention of recurrent urinary tract infections? A randomized controlled trial in older women. J Antimicrob Chemother 2009;63:389-95.

28. Avorn J, Monane M, Gurwitz JH, Glynn RJ, Choodnovskiy I, Lipsitz LA. Reduction of bacteriuria and pyuria after ingestion of cranberry juice. JAMA 1994;271:751-4. 


\title{
Editorial
}

\section{Urinary Tract Infection in Postmenopausal Women}

\author{
Kurt G. Naber \\ Technical University, Munich, Germany
}

Corresponding Author:

Kurt G. Naber. Technical University, Munich, Straubing, Karl-Bickleder-Str, 44c, Germany. TEL: +49942133369, E-mail: kurt@nabers.de

Urinary tract infection (UTI) is the most common bacterial infection in women in general and in postmenopausal women in particular. Whereas UTI in otherwise healthy women is considered as 'uncomplicated' UTI, in some guidelines, UTI in postmenopausal women is considered as 'complicated' UTI. Such a generalization may not be justified, however, because the different situation of the host in this population has to be considered more carefully. In his article on UTI in postmenopausal women, Raul Raz substratifies the population into at least two groups regarding age and general status: 1) (otherwise) healthy, young postmenopausal women aged about 50 to 70 years who are neither institutionalized nor catheterized, and 2) elderly (functionally impaired) institutionalized women with or without a urinary catheter. Concerning impact and outcome, UTI in the first group is much more closely related to 'uncomplicated' UTI in otherwise healthy premenopausal women than to the 'complicated' UTI found in patients with underlying urological anomalies. In the Antimicrobial Resistance Epidemiology in Females with Cystitis (ARESC) study [1], the proportion of Escherichia coli in symptomatic, uncomplicated cystitis of 1,261 premenopausal, nonpregnant women without diabetes mellitus and without recurrent UTI (two or more within 6 months or three or more within 1 year) was $80.8 \%$ and not significantly different from the proportion $(80.3 \%$ ) in 762 (otherwise healthy) postmenopausal women without diabetes mellitus and without recurrent UTI up to an age of 65 years.

TABLE 1. Host risk factors in urinary tract infections categorized according to the ORENUC system

\begin{tabular}{|c|c|c|}
\hline Phenotype & Category of risk factor & Examples of risk factors \\
\hline $\mathrm{O}$ & NO known risk factor & Otherwise healthy premenopausal women \\
\hline $\mathrm{R}$ & Risk factors for Recurrent UTI, but no risk of more severe outcome & $\begin{array}{l}\text { Sexual behaviour (frequency, spermicide) } \\
\text { Hormonal deficiency in postmenopause } \\
\text { Secretor type of certain blood groups } \\
\text { Well-controlled diabetes mellitus }\end{array}$ \\
\hline $\mathrm{E}$ & Extra-urogenital risk factors with risk of more severe outcome & $\begin{array}{l}\text { Prematurity, newborn } \\
\text { Pregnancy } \\
\text { Male gender } \\
\text { Badly controlled diabetes mellitus } \\
\text { Relevant immunosuppression (not well defined) }\end{array}$ \\
\hline $\mathrm{N}$ & Nephropathic diseases with risk of more severe outcome & $\begin{array}{l}\text { Relevant renal insufficiency (not well defined) } \\
\text { Polycystic nephropathy } \\
\text { Interstitial nephritis, e.g., due to analgetics }\end{array}$ \\
\hline $\mathrm{U}$ & $\begin{array}{l}\text { Urological risk factors with risk of more severe outcome, which can } \\
\text { be resolved during therapy }\end{array}$ & $\begin{array}{l}\text { Ureteral obstruction due to a ureteral stone } \\
\text { Well-controlled neurogenic bladder disturbances } \\
\text { Transient short-term external urinary catheter } \\
\text { Asymptomatic bacteriuria }^{\text {a }}\end{array}$ \\
\hline $\mathrm{C}$ & $\begin{array}{l}\text { Permanent urinary Catheter and nonresolvable urological risk } \\
\text { factors with risk of more severe outcome }\end{array}$ & $\begin{array}{l}\text { Long-term external urinary catheter } \\
\text { Nonresolvable urinary obstruction } \\
\text { Badly controlled neurogenic bladder disturbances }\end{array}$ \\
\hline
\end{tabular}

${ }^{a}$ : Only under certain circumstances in combination with other risk factors, e.g., pregnancy, urological intervention. From Truls et al [3] 
Therefore, UTI in this group of postmenopausal women was considered 'uncomplicated' in the recently published German guideline on uncomplicated UTI [2]. UTI in the second group as described by Raul Raz has to be considered at least as 'health care associated' and most often also as 'complicated' if the patient is catheterized or if other complicating factors are present. It is also important to consider the risk factors for recurrent UTIs, which are also common in postmenopausal women. For the first group aged between 50 and 70 years, these are mainly lack of estrogen, urogenital surgery, incontinence, cystocele, postvoid residual urine, prior UTI, and nonsecretor status. For the second group aged over 70 years, these are mainly catheterization, incontinence, urogenital surgery, diminished mental status, and former antimicrobial treatment. Also important is to note that there was no increase in mortality related to bacteriuria for otherwise healthy individuals. Bacteriuria per se did not appear to be a risk factor for mortality. Therefore, asymptomatic bacteriuria in elderly women should not be treated with antibiotics according to Raul Raz's recommendation. In general, treatment of acute cystitis and pyelonephritis in otherwise healthy postmenopausal women is similar to that in premenopausal women. In general, the application of the new ORENUC classification of UTI as proposed by the EAU/ESIU does better to differentiate between postmenopausal status per se (in otherwise healthy women) as a risk factor (for example, for recurrent UTI) and postmenopausal status combined with other risk factors (e.g., nephropathies or uropathies) (Table 1) than does the classic system in which UTI is only substratified into 'complicated' and 'uncomplicated' UTI [3]. For prevention of recurrent UTI, the alarming increase in multidrug-resistant uropathogens makes it imperative to consider and to evaluate alternative strategies as pointed out by Raul Raz in his article.

\section{REFERENCES}

1. Naber KG, Schito G, Botto H, Palou J, Mazzei T. Surveillance study in Europe and Brazil on clinical aspects and antimicrobial resistance epidemiology in females with cystitis (ARESC): implications for empiric therapy. Eur Urol 2008;54:1164-78.

2. Wagenlehner FME, Schmiemann G, Hoyme U, Fünfstück R, Hummers-Pradier E, Kaase M, et al. Epidemiology, diagnostics, therapy and management of uncomplicated bacterial community acquired urinary tract infections in adults. Chemother J 2011; 20:158-68.

3. Johansen TEB, Botto H, Cek M, Grabe M, Tenke P, Wagenlehner FME, et al. Critical review of current definitions of urinary tract infections and proposal of an EAU/ESIU classification system. Int J Antimicr Agents 2011;38S:64-70. 